\title{
PROJETO DE UM PÍER PARA UM PORTO FLUVIAL COM DIMENSIONAMENTO ESTRU- TURAL DA VIGA PRINCIPAL
}

\section{André Ricardo Silva Pereira}

Bacharel em Engenharia Civil pelo Centro Federal de Educação Tecnológica Celso Suckow da Fonseca (CEFET-RJ), Rio de Janeiro, RJ, Brasil.

andrerspereira@gmail.com

\section{Marcos Araujo Braz de Oliveira}

Mestre em Engenharia Civil pela Universidade Federal Fluminense (UFF), Rio de Janeiro, RJ, Brasil.

ma_braz@terra.com.br

\section{Ricardo Rodrigues de Araujo}

Doutor em Estruturas pela Pontifício Universidade Católica do Rio de Janeiro (PUC), Rio de Janeiro, RJ, Brasil.

ricardo.araujo@cefet-rj.br

\section{RESUMO}

Em vista a importância portuária para o transporte de mercadorias e pessoas tanto no âmbito nacional como nas relações comerciais internacionais, sendo responsável pela movimentação de quantidades significativas de capital, trata-se de um estudo acerca das ações atuantes em um píer fluvial proposto por Costa (2016). Considera-se o método de dimensionamento dos respectivos valores em conformidade com normas internacionais, adotando os valores de solicitação mais conservadores para que o resultado obtido seja favorável a segurança. Após o dimensionamento dos esforços elabora-se uma modelagem computacional através do software de modelagem estrutural em 2D, Ftool. Através da modelagem obtém-se as solicitações críticas da estrutura, sendo dimensionada a estrutura para resistir aos esforços de forma segura. 
Palavras-chave: Porto. Estrutura. Píer. Carregamento. Dimensionamento.

\title{
PROJECT OF A PIER FOR A FLUVIAL PORT WITH STRUCTURAL SIZE OF THE MAIN BEAM
}

\begin{abstract}
In view of the portuary importance for goods and people transport, either national as international relationship trademarket, being responsible by transit of significant quantity of money, this work treaths about pier structural loadings acting at a fluvial port proposed by Costa (2016). Considering the metod of sizing of those values according with internationals standards, adopting most conservative requests in order to obtain results that are conducive to security. After evaluate actions, a 2D computational modeling was done through structural software, Ftool. Using the modeling determines critical solicitations of the structure, being the structure sized to resist the request securely.
\end{abstract}

Keywords: Port. Structure. Pier. Loading. Sizing.

\section{INTRODUÇÃO}

Os portos, áreas abrigadas das ondas e correntes, são uma peça chave para o uso de mares e rios como forma de transporte de mercadorias e pessoas, no Brasil e no mundo. Dada a importância dos portos, objetiva-se dimensionar a viga principal de um porto fluvial. É importante a ciência que o píer será dimensionado em seu estado limite último operacional, segundo a normativa espanhola, "Recomendações para Obras Marítimas (R.O.M.)", pois assim faz-se possível avaliar as perdas sofridas pela estrutura devido à dinâmica marítima e atmosférica.

O porto o qual o píer é objeto deste artigo é definido em Costa (2016). Sendo parte de uma rede logística de transporte hidroviário, paralela à rede utilizada atualmente pela TERFON (Terminal Fronteira Norte), Figura 1, que visa atender a demanda exis- 
tente do escoamento da produção de grãos de soja produzidos no centro-oeste do país, este necessita chegar ao litoral para exportação. A localização para o empreendimento será na Baia do Capim, Pará - Brasil, Figura 2.

Figura 1 - Rede de hidrovia proposta e rede utilizada

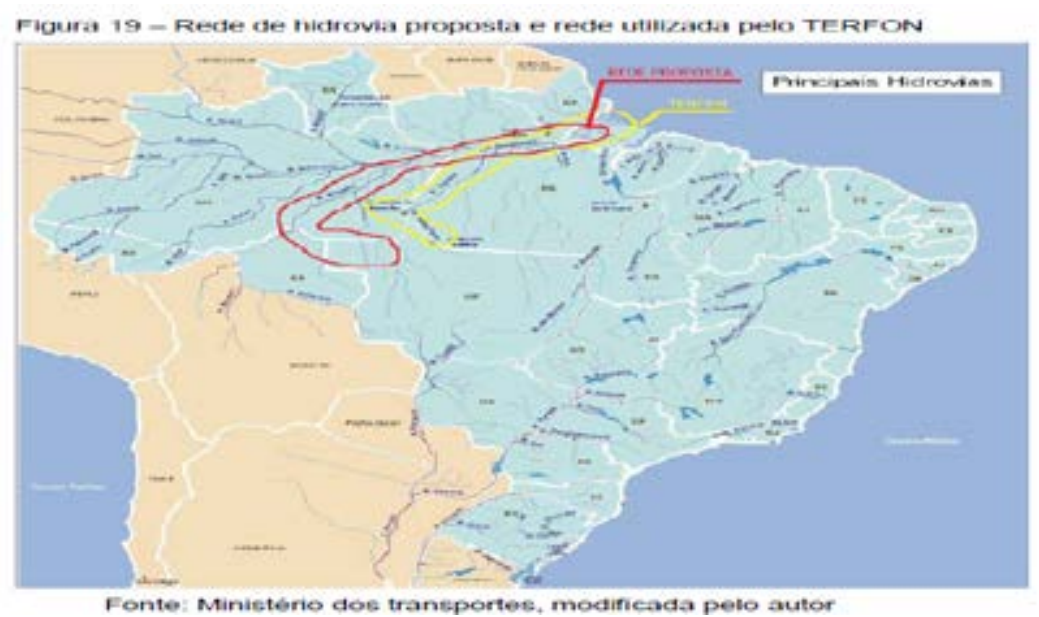

Fonte: Costa (2016)

Figura 2 - Vista da Baia do Capim - Estado do Pará

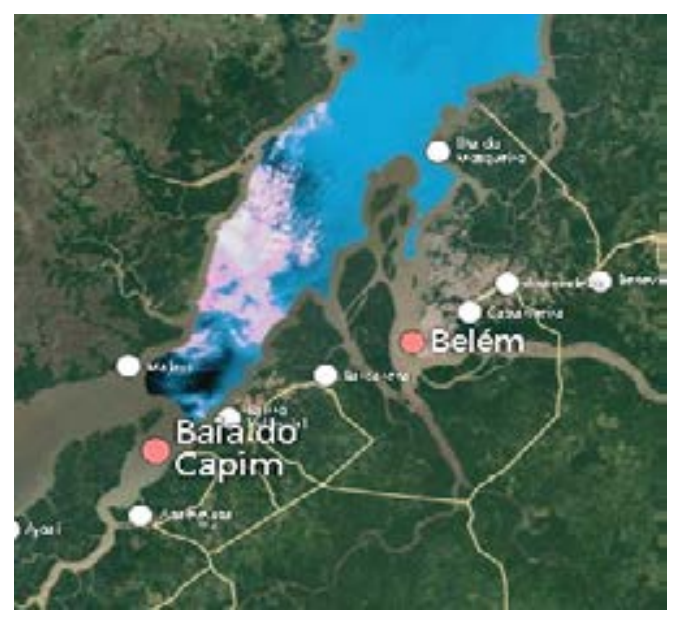

Fonte: Costa (2016)

Além da localização do porto, o autor define o píer, que será estudado neste pre- 
sente estudo, como parte de um porto organizado, ligado ao retroporto por uma esteira rolante que será responsável por transportar os produtos. Sua estrutura é constituída de duas vigas principais, longitudinais aos berços de atracação, apoiadas em estacas.

\section{PREMISSAS}

\subsection{Base técnica}

Este artigo se baseia na NBR 9782 (ABNT, 1987) “Ações em Estruturas Portuárias, Marítimas ou Fluviais", que recomenda que seja considerado, em favor da segurança, a pior configuração de combinação de cargas dentre: permanentes, sobrecargas verticais, cargas móveis e ambientais, cargas de atracação e de amarração. Entretanto, a norma em questão foi cancelada no ano de 2015 por não ser usada pelo segmento, de tal forma que se utiliza as informações desta norma não com teor normativo, mas com orientativo. Utiliza-se, também, as considerações do livro “Obras Portuárias" de Mason (1983) quanto aos esforços atuantes em um píer, visto seu reconhecimento acadêmico e domínio no assunto frente à especificidade do assunto, como complemento à norma no quesito das forças dinâmicas. Para suprir a carência de conteúdo normativo utiliza as normativas: da Espanha "R.O.M."; as normas equivalentes a esta, dos Estados Unido da América - United Facilities Criteria e; do Reino Unido - British Standard. Estas duas por intermédio de Bianco (2015).

\subsection{Configuração}

Para entender os esforços atuantes é necessário definir uma embarcação de projeto, visto que alguns dos esforços são provenientes de ações da própria embarcação, sendo esta uma barcaça de 2.000 tonelagem de peso bruto (TPB) e as seguintes características, as quais são representadas na Figura 3: 
- Comprimento total (L) - 61,0 m, consistindo na distância no eixo longitudinal do navio entre os extremos do mesmo;

- Boca (B) - 10,0 m, distância entre os pontos extremos do costado, na seção transversal do navio;

- Pontal (p) - 5,5 m, altura total do casco do navio;

- Calado (D) - 4,0 m, altura entre a linha de flutuação e a quilha;

- Tonelagem de Porte Bruto (TPR) - 300.000 kg, peso da embarcação vazia;

- Tonelagem de Porte Útil (TPU) - 1.700 .000 kg, sendo a diferença entre o deslocamento em carga e vazio.

Figura 3 - Esquemático das características da embarcação
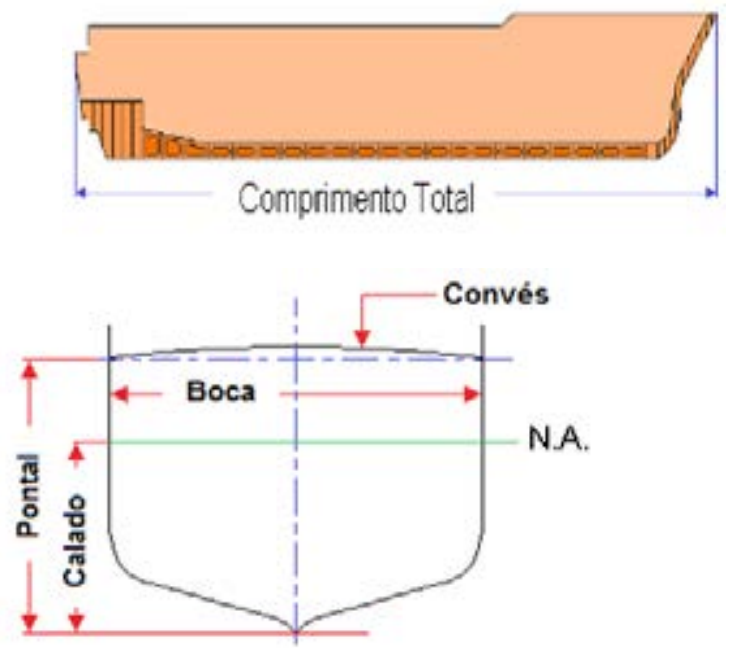

Fonte: Adaptado de CT Borracha

Faz-se necessário ter ciência da sistematização do píer deste artigo, que consiste em uma plataforma de 130 m de comprimento e 12 m de largura, de concreto armado, apoiado em vigas e, estas, em estacas. Ao longo destes $130 \mathrm{~m}$ há dois berços de atracação destinados a receber simultaneamente uma embarcação de projeto em cada, havendo berços somente em um lado do píer. Visto isto, sabendo que o píer será calcu- 
lado considerando o pior caso de aplicação das ações, de forma a garantir a segurança, e ainda, observando que não há possibilidade de embarcações fazerem manobra de atracação e ou desatracação simultaneamente, será considerado caso em que uma embarcação esteja atracada e amarrada enquanto a outra faça sua manobra de atracação.

Este estudo considera duas vigas principais, representadas na Figura 4 retangulares, paralelas aos bordos do píer, que apoiam vigas secundárias perpendiculares aos bordos e uma laje de 0,30 m de espessura, considerada contínua, ainda que seja concretado o paramento de ligação do pré-moldado. $O$ píer deste estudo é representado pelas Figura 5 e Figura 6, que consistem nos cortes do píer com os elementos que o compõe, assim como a ampliação prevista por Costa (2016), no corte transversal.

Figura 4 - Sistema estrutural do píer com vigas principais em destaque

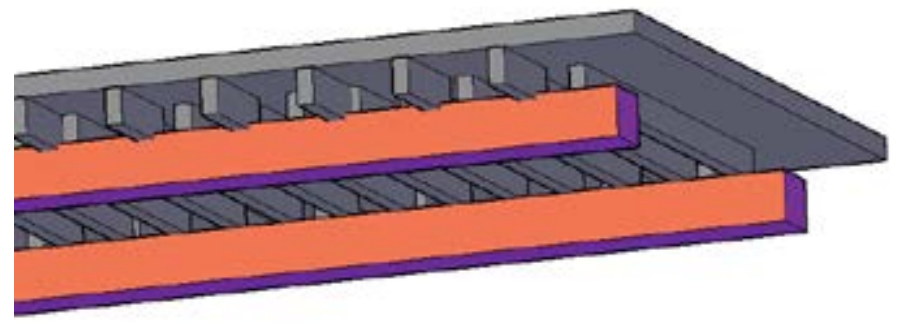

Fonte: Desenvolvido pelo autor, AutoCad

Figura 5 - Corte transversal do píer, medidas em $\mathrm{cm}$

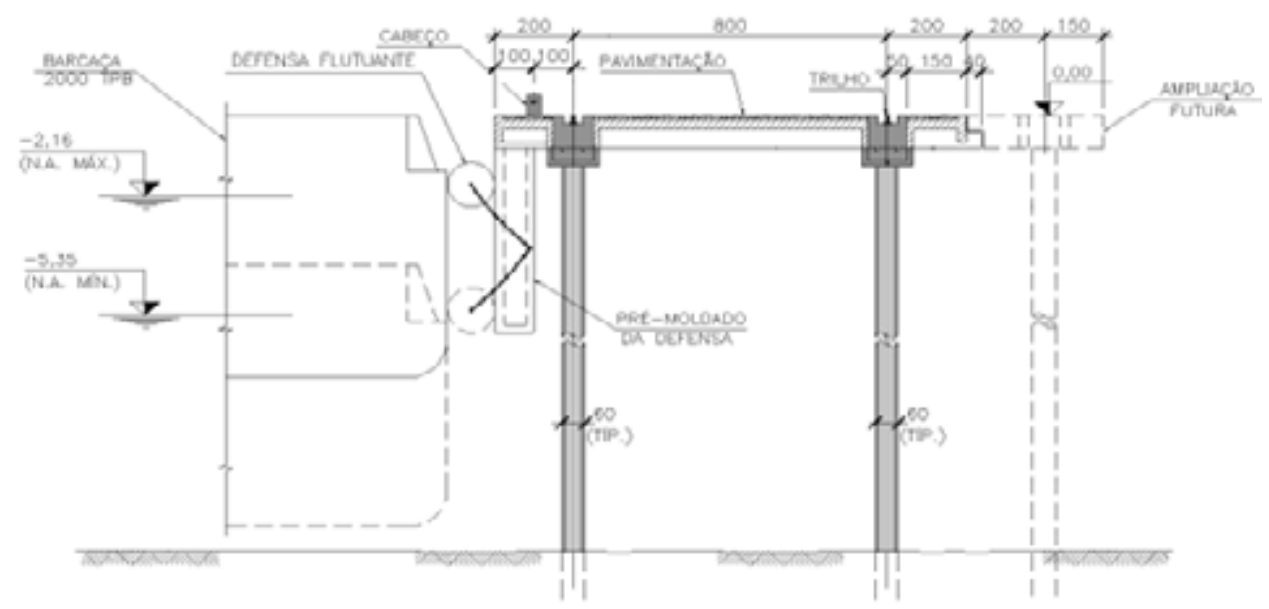

Fonte: Adaptado de Costa (2016) 
Figura 6 - Corte longitudinal do píer

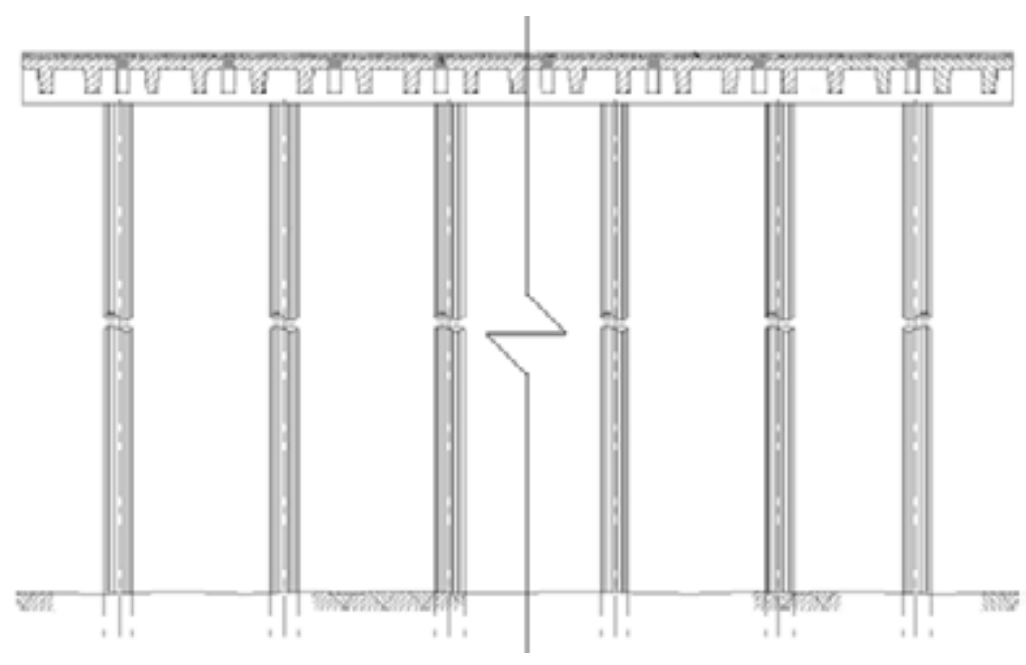

Fonte: Adaptado de Costa (2016)

3 CARGAS

\subsection{Cargas permanentes}

Dentro desta categoria apresentam-se a carga de peso próprio, carga da pavimentação e carga do peso próprio dos paramentos de amarração. O concreto armado utilizado possui peso específico de $25 \mathrm{kN} / \mathrm{m}^{3}$, por determinação da norma. As vigas secundárias, com base no descritivo de Costa (2016), apresentam a constituição apresentada na Figura 7, com base nas dimensões o peso próprio das vigas secundárias corresponde a $3,125 \mathrm{kN} / \mathrm{m}$ em suas extensões. 
Figura 7 - Viga tipo entre: (a) vigas principais (b) entre viga principal e bordo. Unidades em $\mathrm{cm}$.

(a)

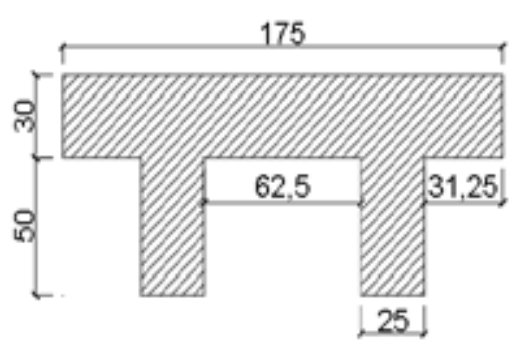

(b)

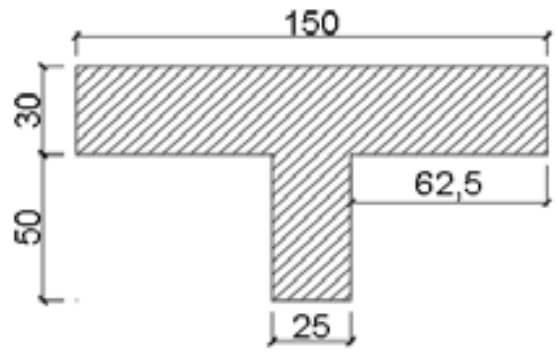

Fonte: Desenvolvido pelo autor (2018)

Para este estudo serão consideradas vigas retangulares e uma laje de 0,30 m de espessura, contínua, ainda que seja concretado o paramento de ligação do pré-moldado, sua configuração foi representada na Figura 4, com as vigas principais destacadas. Acarreta um carregamento de $7,5 \mathrm{kN} / \mathrm{m}^{2}$, aplicado em toda superfície da mesma.

As vigas principais foram pré-dimensionadas com altura de $1,15 \mathrm{~m}$ e base de 1,00 m. Consequentemente a carga de peso próprio em sua extensão corresponde a 28,75 $\mathrm{kN} / \mathrm{m}$. Será utilizada pavimentação de cimento simples com 0,1 $\mathrm{m}$ de espessura e peso específico, determinado pela referida norma, igual a $24 \mathrm{kN} / \mathrm{m}^{3}$. Os pré-moldados das defensas calculados no item 3.5 deste estudo, apresentam carga de 8,0 kN cada, a ser transferido à estrutura por dois pontos de concretagem espaçados de 1,75 m nos locais em que se situarem as defensas.

Os paramentos de amarração calculados no item 3.6 deste estudo, apresentam carga atuante calculada no item 3.6.3 deste estudo e através do catálogo de produtos da empresa COPABO Infra foi selecionado com cabeços de resistência a $500 \mathrm{kN}$ cujos pesos próprios equivale a $1 \mathrm{kN}$.

\subsection{Sobrecargas verticais}

Definido pela norma como ações uniformemente distribuídas aplicadas às es- 
truturas para representar ações de natureza não definida que podem ocorrer durante a vida útil, para determinação do utiliza-se a Tabela 1 da NBR 9782 (ABNT, 1987), obtendo a carga de $30 \mathrm{kN} / \mathrm{m}^{2}$.

\subsection{Cargas Móveis}

Definido pela NBR 9782 (ABNT, 1987) Ações em Estruturas Portuárias, Marítimas ou Fluviais como ações variáveis normais provenientes de veículos, composições ferroviárias, equipamentos móveis sobre trilhos, rodas, esteiras ou pneus. Para o presente estudo considera-se torre sugadora da marca sueca Siwertell, representada na Figura 8. Cuja estrutura consiste na torre apoiada em dois trilhos, estes posicionados sob as vigas longitudinais, ou seja, paralelos ao berço de atracação do píer.

Segundo fabricante seu peso por torre corresponde a $600.000 \mathrm{~kg}$. Sendo dividido igualmente entre os três "trucks", cada um recebendo 2.000 kN, e cada um destes formado por um conjunto de três rodas que se deslocam sobre trilho. A estrutura se locomove sob dois trilhos. Sob o trilho, posicionado mais próximo do berço de atracação, correm dois dos "trucks", sendo 4.000 kN sob o trilho, enquanto no trilho mais distante atua o terceiro conjunto de rodas, recebendo $2.000 \mathrm{kN}$. 
Figura 8 - Equipamento Siwertell



Fonte: Siwertell

O peso próprio da esteira rolante e da carga que está sendo transportada pela esteira. Através da R.O.M., obtém-se o valor representativo de $30 \mathrm{kN} / \mathrm{m}^{2}$ aplicado nos trechos os quais correspondem à passagem da esteira rolante. Entretanto, em decorrência de se tratar de uma análise linear e elástica, a carga do equipamento será considerada estática. De tal forma que será desconsiderado os efeitos da vibração existentes no deslocamento do equipamento.

A carga vertical do equipamento, será posicionada na pior situação, ou seja, na posição que mais solicitar a estrutura do píer deste estudo, posição crítica. Desta forma, a posição considerada será um ponto em que o equipamento estacione para carregar uma embarcação, visto isso o local precisa ser próximo de uma das portas do porão de carga das barcaças, considerando que este local estará sujeito a ação do carregamento mais frequentemente que os outros pontos, e que a torre estará apenas se deslocando. Para o peso próprio do trilho, será considerado um trilho ferroviário certificado pela norma dos Estados Unidos da América, o perfil 141AB, com aproximadamente 0,7 kN/m próprio, sendo o carregamento aplicado longitudinalmente no píer, sobre as vigas principais. 


\subsection{Meio Ambiente}

As cargas apresentadas neste tópico, segundo a NBR 9782 (ABNT, 1987), são oriundas de ações do meio ambiente atuando sobre as estruturas portuárias, dentre as quais são essas em decorrência das ações: do vento, da corrente, da maré e das ondas.

\subsubsection{Cargas devido ao Vento}

A NBR 9782 (ABNT, 1987) elege a NBR 6123 (ABNT, 1988) como parâmetro de cálculo. Para este estudo, é levado em conta a influência dos esforços oriundos da ação do vento no equipamento e na parcela superior da estaca de fundação que estiver a cima do nível da água.

\subsubsection{Cargas devido ao Vento no Equipamento}

Segundo a norma, a pressão de vento sobre a superfície corresponde a 778,64 $\mathrm{N} / \mathrm{m}^{2}$. Considerando as ações dinâmicas do vento e a possibilidade de o vento incidir perpendicular ao píer $\left(90^{\circ}\right)$, Figura $9(\mathrm{a})$, ou longitudinalmente paralelo $\left(0^{\circ}\right)$, Figura $9(\mathrm{~b})$, os valores de carregamento de vento, assim como calculado no Apêndice $A$, são respectivamente e.

Figura 9 - Representação da força e momento gerado por: (a) vento a $90^{\circ}$ (b) vento a $0^{\circ}$.

(a)

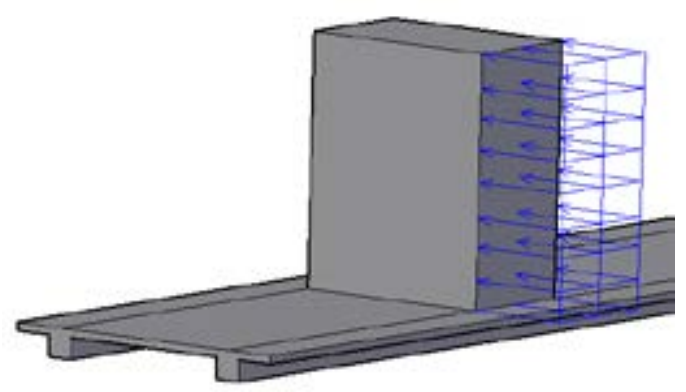

(b)

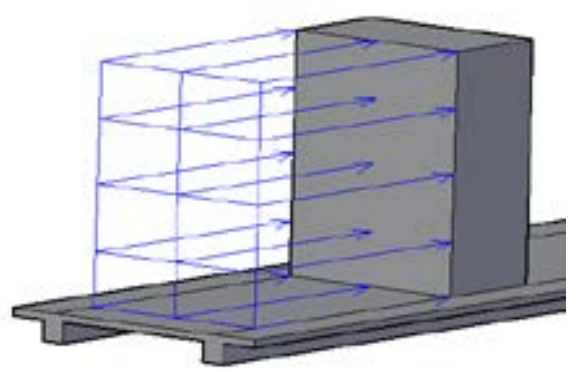

Fonte: Desenvolvido pelo autor, AutoCad

\subsubsection{Cargas devido ao Vento na Estaca}


Com base nos dados determinados por Costa (2016), o desnível da parcela acima do nível da água, em maré baixa, e o topo da estaca consiste em 4,00 m. Essa característica de medição justifica pela obtenção de resultado no pior caso da estrutura, maré baixa. A estaca proposta possui diâmetro de $0,60 \mathrm{~m}$ e é constituída de concreto armado de seção circular. A norma NBR 6123 (ABNT, 1988) orienta o cálculo da força de arraste em estrutura cilíndrica, a força de arrasto é então calculada igual a , aplicada como representado na Figura 10.

Figura 10 - Esquemático da aplicação da resultante da força de arrasto do vento na estaca

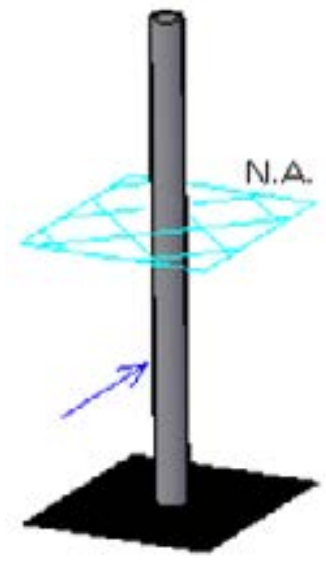

Fonte: Desenvolvido pelo autor, AutoCad

\subsubsection{Cargas devido à Correntes}

Considerado para efeito de cálculo a velocidade da corrente de maré de $2 \mathrm{~m} / \mathrm{s}$. A carga gerada pela corrente é chamada de carga de arraste estático, segundo a NBR 9782 (ABNT, 1987). Sendo considerada no costado submerso das embarcações e na força de arraste hidrodinâmico da parcela submersa da estaca. O esforço da força de arraste é transferido à estrutura portuária sempre que a embarcação estiver atracada. Frente ao exposto, o cálculo é apresentado no item 3.6.3 Carga devido à Amarração deste estudo.

A força de arrasto hidrodinâmica na estaca devido a corrente pode ser calculada segundo o professor mestre em engenharia oceânica Piccini (2008), em seu artigo sobre 
carregamento hidrodinâmico sobre uma estrutura cilíndrica esbelta proveniente de ondas e correntes oceânicas. Obtendo valor da força de arrasto hidrodinâmica igual a 0,494 $\mathrm{kN} / \mathrm{m}$, aplicada na mesma direção e sentido do fluxo da corrente de maré, assim como ilustrado pela Figura 11.

Figura 11 - Esquemático da aplicação da resultante da força de arrasto da corrente na estaca

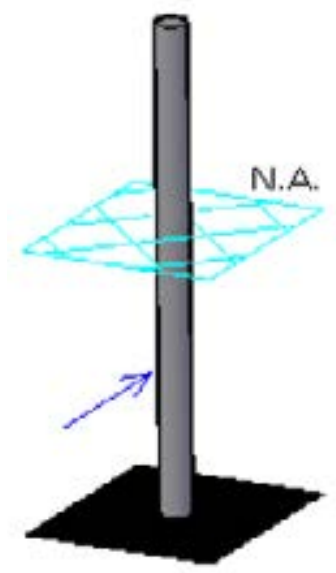

Fonte: Desenvolvido pelo autor, AutoCad

\subsubsection{Cargas devido à Marés}

As cargas oriundas da variação de marés provêm na variação do ponto de aplicação das forças de atracação dos navios no pré-moldado das defensas, na variação da força de arrasto de carregamento do vento da estaca e na força de arrasto da água nas estacas.

De tal forma que se faz necessário a consideração dos diversos casos contidos na variação da maré, a fim de identificar o cenário que representa o pior caso para a estrutura. Para este estudo se considera a variação da maré com amplitude de 3,19 m, entre a maré mais alta e mais baixa. Este valor se justifica por ser o adotado em Costa (2016). Esta variação fica a cargo da combinação de cargas na estrutura. 
A consideração do efeito das ondas se enquadra no perfil de ondas longas da norma norte americana, visto que o píer é construído em local abrigado, como indica Bianco (2015). Para a referida norma o efeito destas ondas se dá como variação da altura do nível d'água. Desta forma, as cargas provenientes das influências de ondas são contempladas nas considerações do efeito de marés.

\subsection{Carga de Atracação}

As cargas provenientes da atracação de embarcações, segundo a NBR 9782 (ABNT, 1987), são impactos da embarcação. Também sendo considerado nesse tópico o impacto da água deslocada pela embarcação.

Segundo Comin (2015), a normativa britânica, BS 6349 (PIANC/EAU 2004), apresenta resultados para energia de atracação cerca de $50 \%$ maior que os demais métodos de cálculo. Através desta obtém-se valor de energia de atração de 120,78tf/m de embarcação, considerando que serão três defensas por embarcação, cada defensa suportará carga de 394,95 kN e estará posicionada de forma distribuída na estrutura, com espaçamentos iguais em relação à embarcação. Com este dado é possível identificar a defensa adequada para o píer, através do catálogo da fabricante ShibataFenderTeam de 2017, adota-se, então, a defensa de espuma, com área de contato de aproximadamente $15,15 \mathrm{~m}^{2}$.

A instalação da defensa necessita de uma estrutura pré-moldada, como demonstrado na Figura 12, que garantirá que a defensa não seja empurrada para baixo do píer e limita o deslocamento lateral. Este pré-moldado será presente somente junto às defensas e concretado junto à laje em dois pontos cada, com distância de 1,75 m, tendo peso próprio, acrescido de peso residual da defensa e correntes que a seguram, arbitrado de $8 \mathrm{kN}$.

Em função do atrito da embarcação com a defensa considera-se 197,48 kN, paralelo à defensa, 50\% da carga perpendicular. Ainda segundo o fabricante, esta defensa 
adotada apresenta absorção de carga aproximada de $23 \%$, transmitindo para a estrutura apenas $77 \%$ do valor aplicado a elas. De tal forma que a estrutura é carregada perpendicularmente com 1.794,26 kN em cada eixo de defensa e 897,15 kN paralelo à linha de defensas em cada uma das defensas, as cargas são ilustradas na Figura 12.

Figura 12 - Representação das cargas nas defensas e pré-moldado de fixação
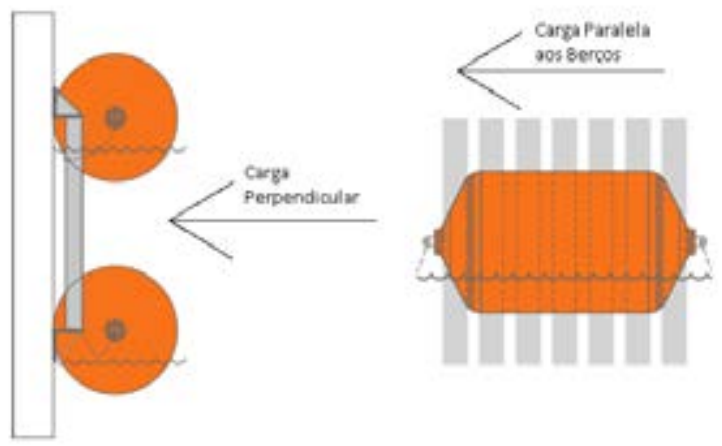

Fonte: Adaptado do catálogo Fender Team (2017)

\subsection{Carga de amarração}

As cargas exercidas pelos cabos, provenientes da amarração de embarcações, atuam nos cabeços ou outros dispositivos de amarração. E, por consequência, são transferidas à estrutura. As cargas de amarração são oriundas das ações as quais as embarcações são objeto, segundo a NBR 9782 (ABNT, 1987).

Segundo o artigo "Estruturas portuárias - distribuição de esforços na estrutura devidos à amarração e atracação de embarcações" de Souza \& Comin (2017), o método proposto pela NBR 9782 (ABNT, 1987) apresenta os resultados mais conservadores para cálculo da carga de amarração. De tal forma a justificar a metodologia adotada neste estudo.

Para mensurar as cargas transmitidas aos cabos é necessário o conhecimento do modelo de amarração, Figura 13. 
Figura 13 - Modelo de amarração

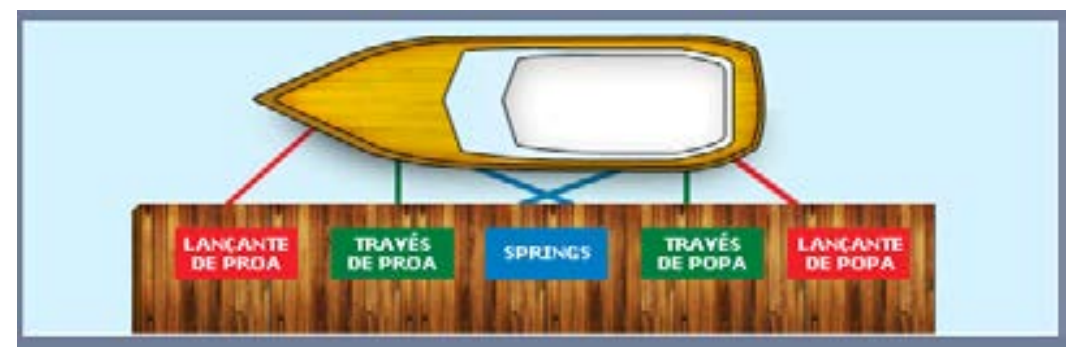

Fonte: CSL Marinharia

Este estudo, usará duas hipóteses de direção do vento: paralela à linha dos berços de atracação $\left(0^{\circ}\right)$ ou perpendicular a esta $\left(90^{\circ}\right)$.

A corrente será paralela ao píer, de leste para oeste, por se tratar de um rio, tendo a corrente o sentido mais provável em direção ao mar, em concordância com preconização da norma.

Ainda se faz necessário saber a angulação que cada cabo faz com o píer. Será considerado, assim como o esquemático da Figura 14, ângulo de $10^{\circ}$ para os springs e $25^{\circ}$ para lançantes, amarrados em dolfin (estrutura apoiada em estaca com finalidade estrutural de amarração de embarcações), quando necessário, as través serão amarradas nos mesmos cabeços nos quais se amarrará os spings.

Figura 14 - Píer com esquemático das amarrações das embarcações

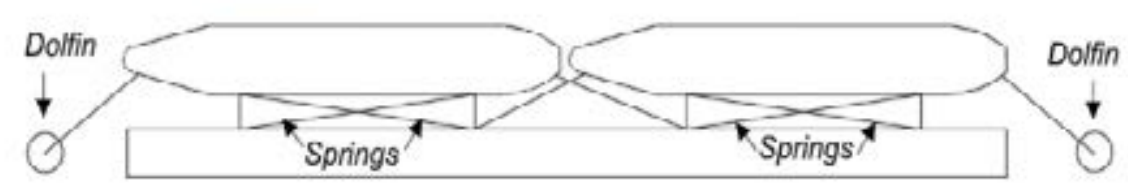

Fonte: Desenwolvido pelo autor, AutoCad. 


\subsubsection{Carga devido ao Vento}

Pode-se determinar o esforço devido ao vento sobre a embarcação levando em conta a velocidade característica do vendo, a área não submersa da embarcação (como ilustra a Figura 15), o ângulo de incidência do vento e o coeficiente de forma da mesma.

A partir da NBR 6118 (ABNT, 2014) o valor da força do vento à $0^{\circ}$ equivale a 68,59 $\mathrm{kN}$ e, à $90^{\circ}$ equivale a $24,53 \mathrm{kN}$.

Figura 15 - Área de atuação do vento em embarcações
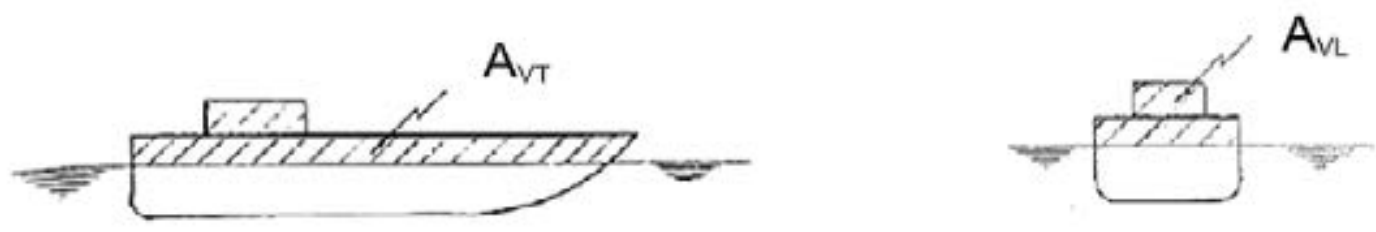

Fonte: Adaptado pelo autor de Mason, 1982

\subsubsection{Carga devido à Corrente}

A ação da corrente é decorrente da ação da água na parcela submersa da embarcação, essa parcela corresponde a área exprimida na Figura 16.

A força de corrente sobre a embarcação é calculada como 1.442,92 kN.

Figura 16 - Área de atuação de corrente em embarcações
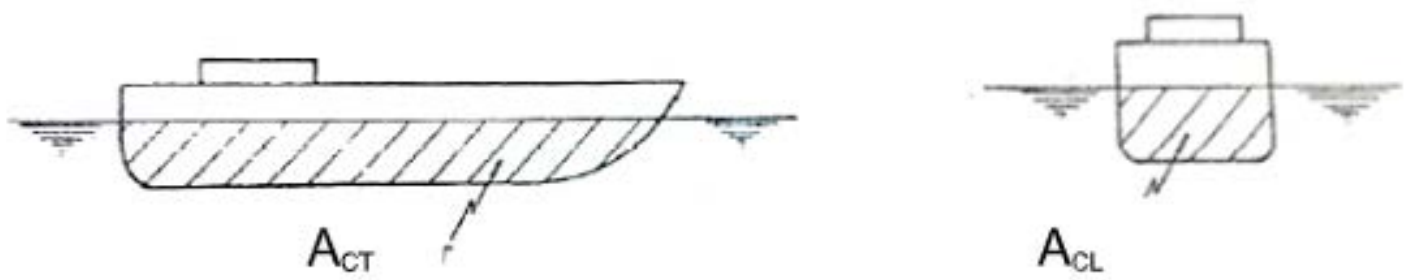

$\mathrm{A}_{\mathrm{CL}}$

Fonte: Adaptado de Mason, 1982 


\subsubsection{Carregamento nos cabeços de amarração}

Calculadas as cargas que atuam na embarcação, calcula-se a tração em cada cabo e, assim, identifica-se o carregamento atuante nos cabeços de amarração. Este, será responsável pela transferência à estrutura do píer.

Os cenários de força de vento e corrente calculados são esquematizados pelas Figura 17 e Figura 18, sendo numerados de 1 a 6 os cabos de amarração da embarcação, sabendo o ângulo entre píer e os cabos, é possível calcular as trações, levando em conta o mínimo determinado por norma de 100 kN.

A posição dos cabeços de amarração é esquematizada na Figura 19, sendo necessário a utilização de 6 cabeços, estes nomeados de A, B, C, D, E e F.

Determina-se qual carga estes recebem individualmente, assim como listado na Tabela 1. Como fator ilustrativo à ação das cargas nos cabeços apresenta-se a Figura 20.

Figura 17 - Esquemático de embarcação com numeração dos cabos de amarração, vento a $90^{\circ}$

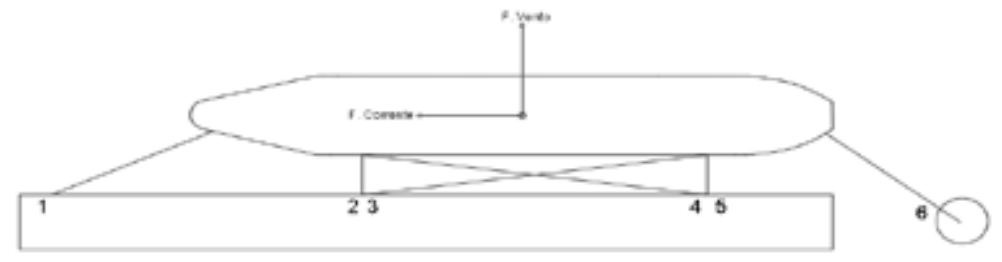

Fonte: Desenvolvido pelo autor, AutoCad.

Figura 18 - Esquemático de embarcação com numeração dos cabos de amarração, vento a $0^{\circ}$



Fonte: Desenvolvido pelo autor, AutoCad. 
Figura 19 - Esquema posição cabeços

(A)

(B) (C)

Fonte: Desenvolvido pelo autor, AutoCad.

Tabela 1 - Carga, em kN, nos cabeços com vento incidindo (a) a $0^{\circ}$ (b) a $90^{\circ}$

(a)

\begin{tabular}{c|c|c} 
Cabeço & $\begin{array}{c}\text { Carga } \\
\text { em X }\end{array}$ & $\begin{array}{c}\text { Carga } \\
\text { em Y }\end{array}$ \\
\hline A & 90,63 & 42,26 \\
B & 98,48 & 117,36 \\
C & 338,72 & 145,98 \\
D & 326,80 & 126,42 \\
E & 248,09 & 103,72 \\
F & 228,32 & 9,06
\end{tabular}

(b)

\begin{tabular}{c|c|c} 
Cabeço & $\begin{array}{c}\text { Carga } \\
\text { em X }\end{array}$ & $\begin{array}{c}\text { Carga } \\
\text { em Y }\end{array}$ \\
\hline A & 90,63 & 42,26 \\
B & 98,48 & 117,36 \\
C & 331,49 & 143,29 \\
D & 312,73 & 123,32 \\
E & 240,86 & 101,03 \\
F & 90,63 & 42,26
\end{tabular}

Fonte: Desenvolvido pelo autor, Excel (2018)

Figura 20 - Píer com esquemático da carga de tração aplicada em cabeço

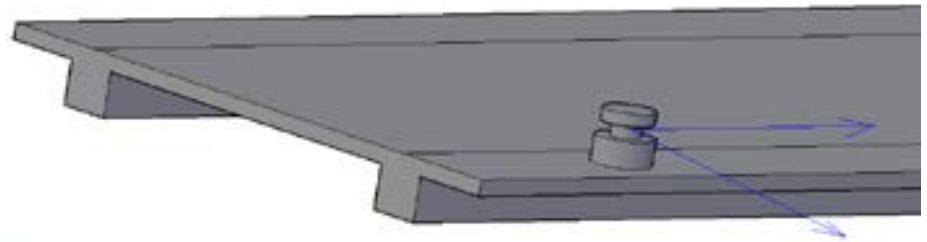

Fonte: Desenvolvido pelo autor, AutoCad

Com base nas cargas atuantes nos cabeços será utilizado cabeços do tipo TEE da fabricante COPABO Infra. Para os cabeços ao longo do píer será utilizado com resistência a até $500 \mathrm{kN}(50 \mathrm{t})$.

Sabe-se que cabeços de amarração devem ser ocos. Por consequência, seu peso próprio não é elevado. Desta forma, devido à falta de informação da fabricante, COPABO Infra, arbitra-se $1 \mathrm{kN}$ de peso próprio para cada cabeço. 


\section{DIMENSIONAMENTO}

Para modelar o píer deste estudo através do Ftool considerou-se as vigas principais como pórticos. Sendo modelada a viga mais próxima ao berço de atracação por ser mais solicitada. A outra viga principal terá armação igual à mais solicitada.

Atuando nestes pórticos estão as cargas calculadas, Tabela 2, para o píer transferidas para as vigas principais de forma equivalente. A configuração das estacas segue o proposto por Costa (2016), representado na Figura 21. As estacas cravadas no solo serão consideradas como apoios de $3^{\circ}$ gênero. A viga principal será a parte de cima do pórtico.

Tabela 2 - Cargas aplicadas no pórtico

\begin{tabular}{|c|c|c|c|c|c|}
\hline Origem & Valor & $\begin{array}{c}\text { Pontual } \\
\text { (kN) }\end{array}$ & $\begin{array}{c}\text { Distribuída } \\
(\mathrm{kN} / \mathrm{m})\end{array}$ & $\begin{array}{l}\text { Momento } \\
(\mathrm{kNm})\end{array}$ & $\begin{array}{l}\text { Ponto de } \\
\text { Aplicação }\end{array}$ \\
\hline Corrente & 0,49 & & $\sqrt{ }$ & - & Estaca \\
\hline Vento & 122,78 & & $\sqrt{ }$ & - & Estaca \\
\hline Pp Viga Principal & 28,75 & & $\sqrt{ }$ & - & Viga \\
\hline $\mathrm{Pp}+\mathrm{SC}$ laje entre vigas & 23,75 & & $\sqrt{ }$ & - & Viga \\
\hline $\mathrm{Pp}+\mathrm{SC}$ laje em balanço & 23,75 & & $\sqrt{ }$ & 62,50 & Viga \\
\hline Pp Cabeços & 1,00 & $\sqrt{ }$ & & - & Viga \\
\hline Pav Laje Interna & 1,50 & & $\checkmark$ & - & Viga \\
\hline Pav Laje Bal & 1,50 & & $\sqrt{ }$ & - & Viga \\
\hline Pp Pré-moldado & 8,00 & $\sqrt{ }$ & & - & Viga \\
\hline Pp Equipamento/roda & 666,67 & $\sqrt{ }$ & & - & Viga \\
\hline Pp trilho & 0,70 & & $\sqrt{ }$ & - & Viga \\
\hline Cabeço 3 & 90,63 & $\sqrt{ }$ & & - & Viga \\
\hline Cabeço 4 & 326,80 & $\sqrt{ }$ & & - & Viga \\
\hline Cabeço 5 & 248,09 & $\checkmark$ & & - & Viga \\
\hline Atracação & 897,15 & $\sqrt{ }$ & & 5382,78 & Viga \\
\hline Viga Secundária Balanço & 25,30 & $d$ & & $-25,30$ & Viga \\
\hline Viga Secundária interna & 62,60 & $\sqrt{ }$ & & - & Viga \\
\hline Vento no Equipamento & 155,73 & $\sqrt{ }$ & & 1946,63 & Viga \\
\hline
\end{tabular}

Fonte: Desenvolvido pelo autor, Excel (2018) 
Por se tratar de uma modelagem 2D as cargas utilizadas serão as que melhor apresentarem condições de serem representadas no programa, as que não houver como serem representadas serão desconsideradas neste estudo simplificado.

A modelagem, feitas as devidas adaptações para que o modelo 2D exprima de forma satisfatória um sistema 3D, considerado como trecho ilustrado na Figura 22, demonstrou os valores de solicitações máximas necessárias para o dimensionamento da viga principal sendo maior: momento fletor negativo como $3.110,0 \mathrm{kNm}$ e o positivo $3.050,1$ kNm; o cortante de 2.975,5 kN; e esforço normal de 1.543,9 kN de compressão.

Em posse dos valores de carga máxima dimensiona-se a viga conforme determinação da NBR 6118 (ABNT, 2014), com resultado demonstrado na Figura 23. Utilizando resistência de concreto de resistência de $30 \mathrm{MPa}$ e aço CA-50. Sabendo que as dimensões adotadas $d$ a viga principal. 
Figura 21 - Configuração das estacas

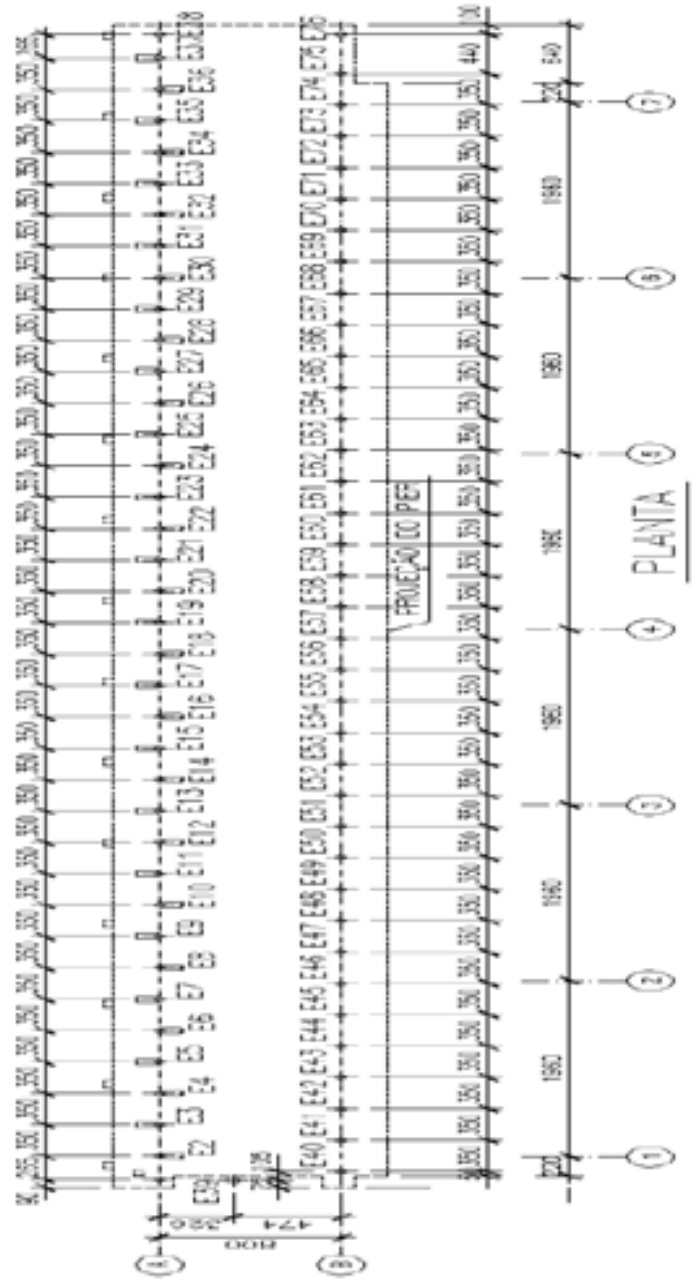

Fonte: Costa (2016) - Esc: 1:750 
Figura 22 - Trecho do píer representado na modelagem com as cargas aplicadas

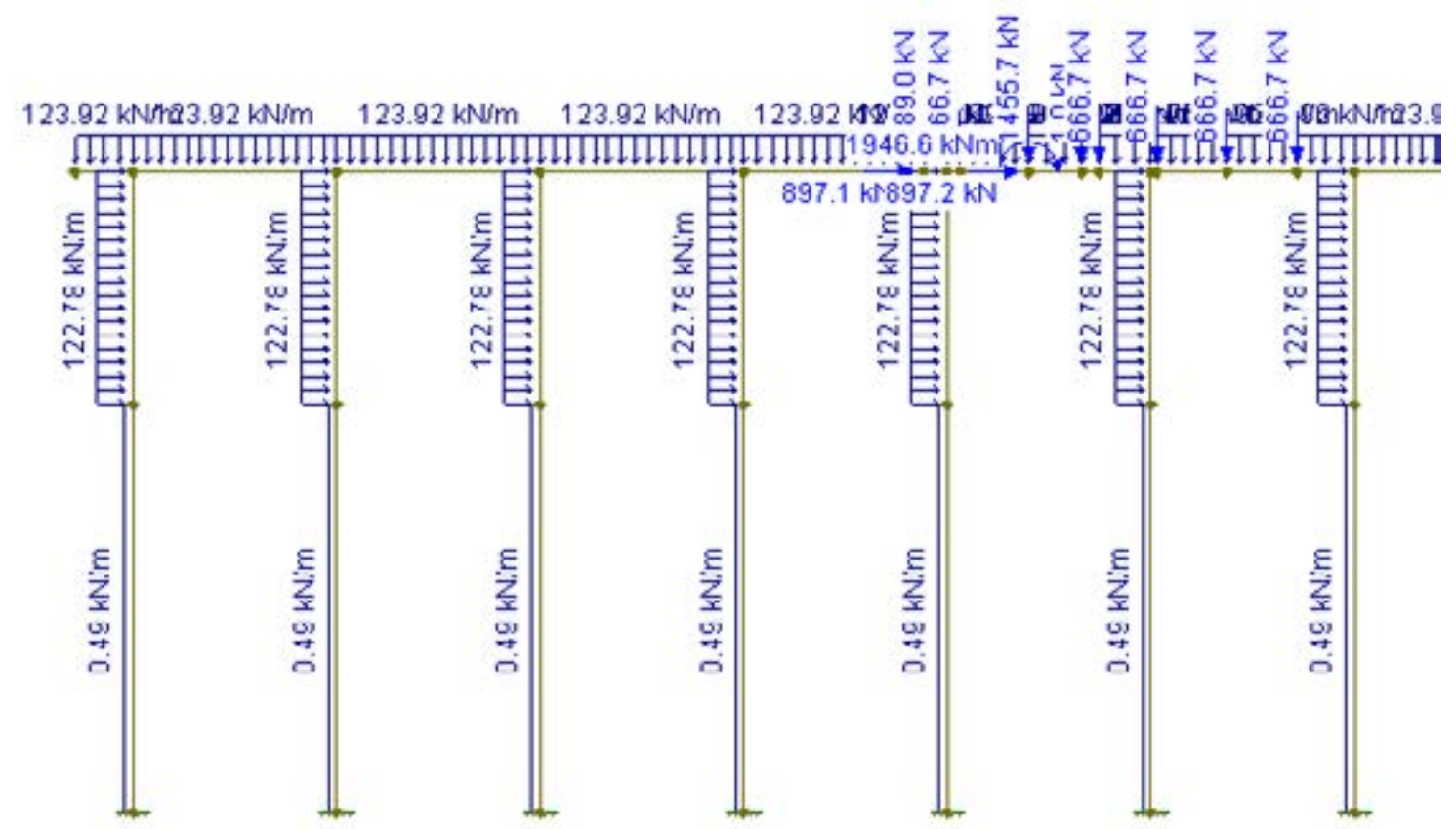

Forte: Desenvolvido pelo autor - Ftool

Figura 23 - Seção transversal armada da viga principal

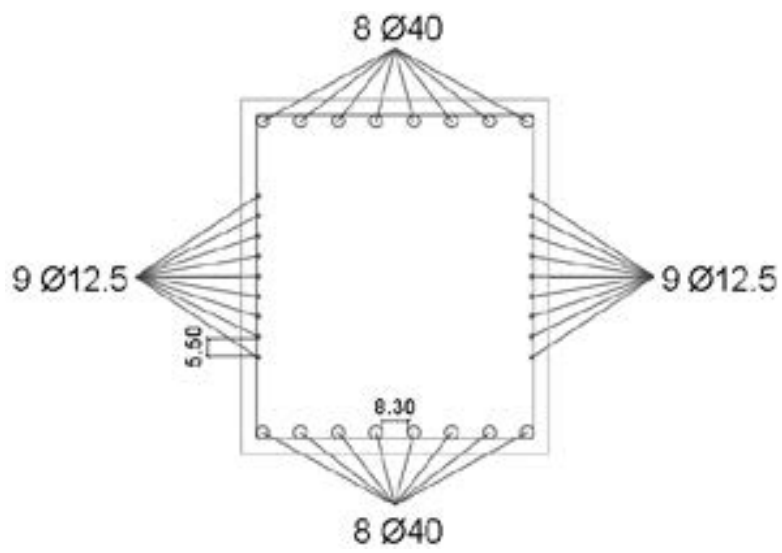

$\varnothing 5-4.00-C / 10$

Forte: Desenvolvido pelo autor, AutoCad 


\section{CONSIDERAÇÕES FINAIS}

Este artigo abordou todas de forma geral todas as cargas atuantes em um píer e seus efeitos no mesmo. Tendo calculado suas ações e dimensionado a viga principal para esta estrutura.

Com base nos esforços calculados é possível calcular a seção transversal adequada à solicitação dos esforços. Através do cálculo do, em concordância com a NBR 6118 (ABNT, 2014). 0 limite adotado de 0,3199 , com base normativa, atende ao intuito que a peça estrutural trabalhe dentro do Domínio 3, o domínio mais econômico e mais seguro de dimensionamento. Os valores obtidos nos cálculos são expressos pela Tabela 3.

Tabela 3 - Cálculo de KMD para diferentes seções de viga

\begin{tabular}{|ccccc|}
\hline $\mathrm{h}$ & $\mathrm{b}$ & $\mathrm{d}$ & \multicolumn{2}{c|}{ Kmd pos Kmd neg } \\
\hline 1,15 & 1 & 1,0925 & 0,11925 & 0,12159 \\
1,15 & 0,9 & 1,0925 & 0,1325 & 0,1351 \\
\hline 1,15 & 0,8 & 1,0925 & 0,14906 & 0,15199 \\
\hline 1,15 & 0,7 & 1,0925 & 0,17035 & 0,1737 \\
\hline 1,15 & 0,6 & 1,0925 & 0,19875 & 0,20265 \\
\hline 1,1 & 0,9 & 1,045 & 0,14482 & 0,14766 \\
\hline 1 & 1 & 0,95 & 0,1577 & 0,1608 \\
\hline 0,9 & 0,9 & 0,855 & 0,21633 & 0,22058 \\
\hline 0,9 & 0,85 & 0,855 & 0,22906 & 0,23355 \\
\hline 0,9 & 0,8 & 0,855 & 0,24337 & 0,24815 \\
\hline 0,8 & 0,8 & 0,76 & 0,30802 & 0,31407 \\
\hline 0,8 & 0,6 & 0,76 & 0,41069 & 0,41875 \\
\hline 0,7 & 0,7 & 0,665 & 0,45978 & 0,46881 \\
\hline
\end{tabular}

Forte: Desenvolvido pelo autor, Excel

Através desta fica evidenciado que a seção transversal da viga proposta poderia ser substituída, sem prejuízo, por uma seção de $0,80 \mathrm{~m}$ de altura e $0,80 \mathrm{~m}$ de base, representado na Figura 24. Tal diminuição da seção transversal da viga correspondendo a um alívio de carga por metro nesta viga. Além da diminuição da área de forma para a execução da obra. 
Figura 24 - Seção transversal pré-dimensionada frente à secessão otimizada da viga principal
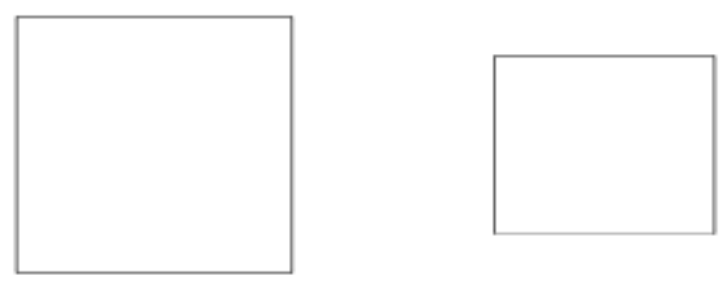

Forte: Desenvolvido pelo autor, AutoCad

\section{REFERÊNCIAS}

ASSOCIAÇÃO BRASILEIRA DE NORMAS TÉCNICAS. NBR 6118: Projeto de estruturas de concreto - Procedimento. Rio de Janeiro, 2014.

ASSOCIAÇÃO BRASILEIRA DE NORMAS TÉCNICAS. NBR 6123: Forças devidas ao vento em edificações. Versão Corrigida 2, 2013. Rio de Janeiro, 1988.

ASSOCIAÇÃO BRASILEIRA DE NORMAS TÉCNICAS. NBR 9782: Ações em estruturas portuárias, marítimas ou fluviais - Procedimento. Rio de Janeiro, 1987.

BIANCO, L. P. O. Critérios de projeto em obras portuárias: uma comparação entre normas brasileira e estrangeiras, Universidade Federal do Rio de Janeiro, Rio de Janeiro, 2015. Trabalho de conclusão de Curso. 
CHAMBERLAIN, Z. AÇOES DO VENTO EM EDIFICAÇÕES. Notas de aula Universidade Passo Fundo, disponível em http://upf.br/ zacarias , acessado em 29/04/2018 9:00.

COMIN, C. Estruturas portuárias - Distribuição de esforços na infraestrutura devidos à amarração e atracação de embarcações, Universidade Federal do Pará. Instituto de Tecnologia, Pará, 2016. Tese de Mestrado.

COMIN, C.; De SOUZA, R. M. Estruturas protuárias - distribuição de esforços na infraestrutura devidos à amarração e atracação de embarcações. Revista Ibracon de Estruturas e Materiais. 10, n. 3, Jun2017. 626-652.

COPABO Infra. Catálogo de defensa marítima. Catálogo de equipamentos portuários, Brasil, 2018?, disponível em https://pt.calameo.com/books/000162398512c0e8b6645, acessado em 27/06/2018 às 19:15.

COSTA, J. P. M. I.. Projeto de um píer para um porto fluvial, com dimensionamento das vigas principais, Centro Federal de Educação Tecnologica Celso Suckow da Fonseca (CEFET), Rio de Janeiro, 2016. Trabalho de conclusão de curso.

CSL Marinharia. Modelo de Amarração. Disponível em http://cslmarinharia.com.br/produtos/detalhes/espias, acessado em 14/04/2018 às 9:30.

CT Borracha. Esquemático das características da embarcação. Disponível em https:// 
ctborracha.com/?page_id=, acessado em 04/05/2018 às 17:10.

GRAVATÁ, Edgar Gulden, Notas de aula Estruturas II, CEFET/RJ, Rio de Janeiro, 2015.

MASON, Jayme. Obras portuárias. 2.ed. Rio de Janeiro: Campus, 1983.

PICCININI, F. C. Carregamento hidrodinâmico sobre uma estrutura cilíndrica esbelta proveniente de ondas e correntes oceânicas. Revista da Engenharia de Instalações no Mar. Sci. n. 1, Jan/Jun2008. 1-10.

POWERPORT. Amarração. Catálogo de equipamento portuário, Espanha, (2013?).

R.O.M., Recomendação para Obras Marítimas. Governo da Espanha, Espanha, 2005.

Siwertell. Catálogo de Equipamentos - Torre sugadora. Disponível em http://www. siwertell.com, acessado em 04/07/2018 às 17:24.

SHIBATA FENDERTEAM. Design Manual. Catálogo de defensas, Alemanha, 2017. 